\title{
Antibiotic prophylaxis in dentistry: part II. A qualitative study of patient perspectives and understanding of the NICE guideline
}

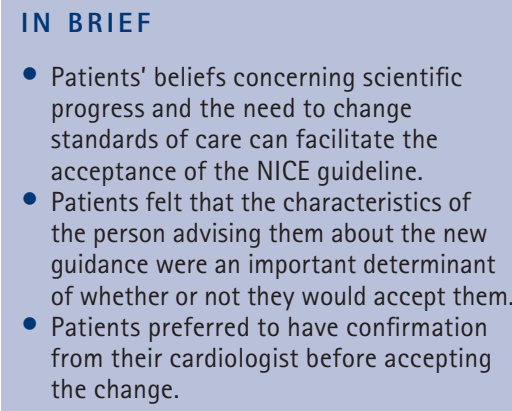

\author{
S. Soheilipour, ${ }^{1}$ S. Scambler, ${ }_{1}^{2}$ C. Dickinson, ${ }^{3}$ S. M. Dunne, ${ }^{4}$ M. Burke, ${ }^{5}$
}

S. E. Jabbarifar, ${ }^{6}$ and J. T. Newton ${ }^{7}$

Background The National Institute for Health and Clinical Excellence (NICE) recommendations in 2008 for antibiotic prophylaxis before dental treatment contradict previous practice. There is a potential difficulty in explaining the new guidance to patients who have long believed that they must receive antibiotics before their dental treatment. Aim This study investigated the patient-related barriers and facilitating factors in implementation of the NICE guidance. Methods In-depth interviews were conducted with nine patients concerning their views about barriers and factors that could influence the implementation of the NICE guidance on antibiotic prophylaxis before dental treatment. Data were analysed using framework analysis. Results For patients the rationale for the NICE guidance was unclear. They understood that at the population level the risk of infective endocarditis was less than the risk of adverse reaction to antibiotics. However, on an individual level they felt that the latter risk was negligible given their previous experience of antibiotics. They were aware that standards of care change over time but were concerned that this may be an example where a mistake had been made. Patients felt that the characteristics of the person advising them about the new guidance were important in whether or not they would accept them - they wished to be advised by a clinician that they knew and trusted, and who was perceived as having appropriate expertise. Conclusions Patients generally felt that they would be most reassured by information provided by a clinician who they felt they could trust and who was qualified to comment on the issue by respecting their autonomy. The implications of the findings for the development of patient information are discussed.

\begin{abstract}
Department of Oral Health Services Research \&t Dental Public Health, GKT Dental Institute, King's College London, Caldecot Road, Denmark Hill, London, SE5 9RW/ Member of Faculty, Department of Community Dentistry, Dental School, Isfahan University of Medical Sciences, Isfahan, Iran: ${ }^{2}$ Lecturer in Sociology, Department of Oral Health Services Research \& Dental Public Health, GKT Dental Institute, King's College London, Caldecot Road, Denmark Hill, London, SE5 9RW: ${ }^{3}$ Consultant in Special Care Dentistry, Guy's and St Thomas' NHS Foundation Trust, Floor 26, Guy's Tower, Guy's Hospital, London, SE1 9RT; ${ }^{4}$ Professor in Primary Dental Care, Head of Dental Practice and Policy, Department of Primary Dental Care, King's College London, Caldecot Road, Denmark Hill, London, SE5 9RW: ${ }^{5}$ Consultant in Special Care Dentistry, Guy's and St Thomas' NHS Foundation Trust, Floor 26, Guy's Tower, Guy's Hospital, London, SE1 9RT; ${ }^{6}$ Associate Professor in Pediatric Dentistry, Department of Pedodontics, Dental School, Isfahan University of Medical Sciences, Isfahan, Iran; ${ }^{7}$ Professor of Psychology as Applied to Dentistry, Deputy Director of Research \& Development, Head of Oral Health, Workforce \&t Education Research Group, Department of Oral Health Services Research \& Dental Public Health, King's College London, Caldecot Road, Denmark Hill, London, SE5 9RW

${ }^{*}$ Correspondence to: Shimae Soheilipour

Email:sh_soheilipour@yahoo.com;

Tel: +44 (0)203299 3481; Fax: +44 (0)2032993409
\end{abstract}

Online article number E2

Refereed Paper - accepted 10 December 2010

DOI: 10.1038/sj.bdj.2011.525

${ }^{\circ}$ British Dental Journal 2011; 211: E2

\section{INTRODUCTION}

Infective endocarditis (IE) is a rare condition with a high mortality and morbidity. The theoretical possibility of a relationship between IE and dental and some non-dental procedures led to the accepted clinical practice of prescribing antibiotic prophylaxis (AP) to those at risk of IE having dental and certain non-dental interventional procedures, in the belief that this may prevent the development of IE. ${ }^{1}$ There is a lack of evidence to support the effectiveness of such AP in humans ${ }^{2}$ and recent guidelines recommend a much more limited role for antibiotic prophylaxis against infective endocarditis., ${ }^{3,4}$ Recently introduced evidence-based guidance from the National Institute for Health and Clinical Excellence (NICE) does not recommend AP for people undergoing dental procedures. $^{3-5}$ The NICE guidance on prophylaxis against infective endocarditis has been widely disseminated in the UK. The Chief Dental Officer and Medical Defence Union have published specific advice for dental practitioners highlighting that antibiotic prophylaxis is no longer required for adults and children with structural heart disease previously designated at risk of infective endocarditis. ${ }^{6,7}$

Many methods have been developed to implement guidelines in everyday practice and facilitate change to clinical care for patients, and studies have been undertaken to evaluate their effectiveness. ${ }^{8}$ The value of these approaches can be different depending on the changes required, the target group, the clinical setting and the barriers and facilitator factors found there. ${ }^{9}$ The NHS Centre for Reviews and Dissemination suggests that 'any attempt to bring about change should first involve a diagnostic analysis to identify factors likely to influence the proposed change. 
Choice of dissemination and implementation interventions should be guided by the diagnostic analysis and informed by knowledge of relevant research.' ${ }^{10}$ A good understanding of factors - both barriers and solutions - that influence the implementation of research findings in clinical practice is one way to carry out a diagnostic analysis. ${ }^{11,12}$ Obstacles may arise at different stages in healthcare systems: at the level of patients, the individual professional, the healthcare team, the healthcare organisation, or the wider environment. ${ }^{11-15}$

This paper explores the impact of the NICE guidance and the resulting change in recommended practice on AP for patients at risk of IE. The guidance provides a 'one size fits all' approach which would appear easy to implement, however, it is not unreasonable to suppose that those patients who have previously taken AP before dental treatment to prevent IE would be concerned when they were advised not to take it. Consequently, patients may have specific beliefs and may expect different care than is proposed in the new NICE guideline.

A recently published quantitative paper reported attitudes to the guideline and implications for dental practice in Ireland but only provided a few insights into patients' concerns about implementation of the new guideline. ${ }^{16}$ This paper presents the results of a qualitative study that explored patient-related attitudes towards implementation of the new NICE guideline on AP in dental settings.

\section{METHOD}

\section{Study design and data collection}

This study used qualitative methods to explore patients' understanding of the new NICE guideline and its implications for future dental treatment. The aim was to generate new ways of perceiving or understanding this social phenomenon ${ }^{17}$ rather than quantifying responses. Semistructured in-depth interviews were conducted with patients attending the Department of Sedation and Special Care Dentistry at King's College London Dental Institute (Guy's Campus) whose cardiac conditions were recognised as a risk factor for infective endocarditis or who had a previous episode of IE. A topic guide, focusing on possible barriers and facilitators for the implementation of the new guideline, was used to ensure consistency in the coverage of key areas but allow for flexibility in developing new themes. Fourteen patients agreed to participate from a sample population of 20 and data saturation, as reflected in repetition of themes, was reached after nine interviews were completed. The interviews lasted between 30 to 50 minutes and all interviews were recorded and transcribed verbatim before analysis. Approval for the study was received from the Research Ethics Committee of King's College Hospital, London, UK (Ref No: 08/H0808/126).

\section{Analysis}

The transcripts were analysed using the framework approach, whereby analytical categories are derived deductively from the data. The Framework Methodology consists of five stages which involve: familiarization; identifying a thematic framework; indexing; charting; and mapping and interpretation. ${ }^{18,19}$ This method is particularly suited to applied or policy relevant qualitative research. An initial thematic framework was developed reflecting the literature and questions derived from the objectives of the study, as well as issues raised by respondents themselves through the familiarisation process. This framework was then checked repeatedly against the interviews and a series of main themes and subtopics were identified. The transcribed interviews were coded and indexed against the framework independently by members of the research team and the coded texts were compared. During the 'charting and mapping' stages, each main theme and its dimensions were refined and displayed in an individual matrix, where every respondent was allocated a row and each column denoted a separate subtopic. Data from each participant were then linked to the appropriate parts of the thematic framework. In the final stage of analysis the data were investigated to find associations between themes and provide explanations for the findings.

\section{RESULTS}

The results of this study showed that there were both positive and negative reactions to the new guidance. A number of interventions to improve patients' understanding of the guidelines were also suggested.
The positive aspects promoted adoption of the new guidance; the negative aspects suggested suspicion of the guidance and resistance to its implementation. Table 1 presents the demographic profile of the participants in the study.

Patients' views of the new guidance on antibiotic prophylaxis are summarised in Table 2. Views on the guidelines are presented first.

\section{Facilitating factors}

The main benefits of the new guidelines were identified as the removal of the need to take medication and the freedom to receive dental treatment within the primary care sector. Avoidance of the potential side-effects of antibiotics was highlighted:

'I prefer not to have antibiotic if possible, not because I am against the antibiotic just because I don't feel well for a couple of days.' (Patient 1, coded P1.2)

Also highlighted was the convenience of accessing local NHS care:

'I don't have to come across London to do my dental care and so it is fine.' (Patient 1, coded P2)

Thus, the removal of the requirement for AP was seen by some as emancipator.

Alongside this, the range of sources of information regarding the guidelines available and accessible to patients was highlighted (see subthemes under P3 in Table 2). High quality information is available on the internet for those confident in using this form of media.

'I am sufficiently sophisticated to use the internet to know what rubbish is and what looks reputable; I can also check that out at somebody else within the profession if that is necessary...' (Patient 1, coded P3.1 \& P3.3)

Others preferred information provided by their clinician:

'I am one of those that if my doctor or dentist says something, I think "oh yes that must be all right." Because if you have confidence then you trust their judgment and what they're telling you.' (Patient 3, coded P3.2)

Overall, the availability of information from a reliable, trusted source was 
identified, by almost all participants, as an effective form of patient reassurance.

There was also an element of trust in the progress of science (theme P4) which encapsulated the idea that continuous progress and new knowledge led to changes in practice.

'I felt from what he told me that the scientific evidence supported the decision that they have made. If there has been significant research, if the evidence is strong then you should just go with them, because there is a risk in everything, isn't there?' (Patient 8, coded P4)

The caveat, however, raised by some participants, was the worry that the research was not conclusive.

'I don't like to be a guinea pig...' (Patient 5 , coded N9)

This was reflected in the knowledge that different guidelines were followed in different countries, with some still using AP and others no longer giving AP.

'I remember my dentist said in America they stopped antibiotic cover for dental treatment some time ago. I suppose medicine like everything seems to be global now.' (Patient 3, coded P5)

'It is in England, because in France they still do it in the same way. They give antibiotic.' (Patient 5, coded N10)

This reflects both the need to trust science and the fear that the trust may be misplaced. In some cases the perceived powerlessness of patients to influence national policy led to capitulation rather than a positive acceptance of the change in practice.

'I know the guideline would be applied in all dental practices across the UK. Therefore the policy would be the same anywhere I go.' (Patient 8, coded P6)

\section{Barriers}

The main barriers to acceptance of the new NICE guidelines stemmed around the fear of IE. This was a particular issue for those patients who had previously experienced infective endocarditis and obviously they were more reluctant to have dental treatment without antibiotics than those with a high risk cardiac condition who had not had IE. They experienced a situation very

\begin{tabular}{|c|c|c|c|c|}
\hline Participant & Gender & Age (years) & $\begin{array}{l}\text { Postgraduate } \\
\text { qualification }\end{array}$ & Medical condition \\
\hline 1 & Male & 50 & Yes & Implantable cardioverter defibrillator \\
\hline 2 & Male & 66 & Yes & Previous infective endocarditis \\
\hline 3 & Female & 61 & No & History of sub-acute endocarditis \\
\hline 4 & Female & 64 & No & Chest pain, pneumonia \\
\hline 5 & Female & 70 & No & Previous infective endocarditis \\
\hline 6 & Female & 62 & No & Previous infective endocarditis (twice) \\
\hline 7 & Male & 62 & No & Previous infective endocarditis \\
\hline 8 & Female & 38 & Yes & Valve replacement \\
\hline 9 & Male & 42 & No & Previous infective endocarditis \\
\hline
\end{tabular}

Table 2 Patients' views on the implementation of the NICE guideline

\begin{tabular}{|c|c|c|}
\hline Facilitating factors & Barriers & Possible interventions \\
\hline $\begin{array}{l}\text { P1: Taking fewer drugs } \\
\text { P2: Convenience of accessing } \\
\text { local NHS care } \\
\text { P3: Source of information: } \\
\text { 1: Internet } \\
\text { 2: Dentist } \\
\text { 3: Professional body } \\
\text { 4: Cardiologist } \\
\text { 5: General practitioner } \\
\text { 6: Hospital } \\
\text { P4: Trust in the progress of } \\
\text { science and changing the } \\
\text { standards of care } \\
\text { P5: The same practice in the } \\
\text { some other parts of the } \\
\text { world by stopping AP } \\
\text { P6: The feeling of having no } \\
\text { power to influence the } \\
\text { national policy }\end{array}$ & $\begin{array}{l}\text { N1: Fear of recurrence of infec- } \\
\text { tive endocarditis } \\
\text { N2: The psychological belief of } \\
\text { accepting AP as an insurance } \\
\text { against IE specially when } \\
\text { patients has not experienced } \\
\text { any side effect } \\
\text { N3: The belief that dental treat- } \\
\text { ment is the main cause of } \\
\text { infective endocarditis } \\
\text { N4: The possibility of being } \\
\text { exposed to an unnecessary } \\
\text { risk } \\
\text { N5: Conflicting opinion of other } \\
\text { medical staff, especially } \\
\text { cardiologists } \\
\text { N6: Changing the guidance due } \\
\text { to a money saving idea } \\
\text { N7: Science progresses: concerns } \\
\text { regarding the effect of } \\
\text { inconclusive research } \\
\text { N8: Using AP in the other parts } \\
\text { of the world } \\
\text { N9: New or inexperienced } \\
\text { dentists: not be treated as } \\
\text { a special care patient in the } \\
\text { hospital }\end{array}$ & $\begin{array}{l}\text { I1: Hearing from somebody with } \\
\text { more authority or profes- } \\
\text { sionals that patients know } \\
\text { and trust } \\
\text { I2: Receiving a consensus } \\
\text { message } \\
\text { I3: Verbal explanation: } \\
\text { - Positive points } \\
\text { - Negative points } \\
\text { - Ineffectiveness } \\
\text { 14: Leaflet or written informa- } \\
\text { tion, reliable websites or on } \\
\text { the TV } \\
\text { 15: Having the opportunity to } \\
\text { discuss when they encounter } \\
\text { two different opinions } \\
\text { 16: Statistic information to sup- } \\
\text { port the guideline } \\
\text { 17: Dealing with each patient } \\
\text { individually and giving the } \\
\text { option of taking antibiotic } \\
\text { prophylaxis if they want } \\
\text { 19: Receiving dental treatment } \\
\text { without AP but in the hospital }\end{array}$ \\
\hline
\end{tabular}

close to death during the acute phase of IE and in some cases, it was perceived that IE had caused a stroke due to late diagnosis, had resulted in lengthy hospital stays, and had resulted in polypharmacy. Understandably, these patients felt particularly vulnerable and scared.

'I have to trust my dentist and cardiologist but the fright is still there because I had it.' (Patient 2, coded N2)

'I will be very apprehensive, very worried. I don't want to go back to being like that again.' (Patient 6, coded N2)
This view was understood but not replicated by high risk patients with no previous episodes of IE.

'If I'd have had IE, I'd probably feel differently and probably keep applying AP.' (Patient 8, coded N2)

AP was seen by some as an insurance against IE. This had positive psychological effects.

'Antibiotics for me is something reassuring me that if I get something this is going to fight for me.' (Patient 5, coded N4.1) 
Moreover, the failure to experience sideeffects from taking antibiotics made the case for $\mathrm{AP}$ as insurance stronger.

'If they gave me antibiotics I am happy because it doesn't give me allergy and I feel safer.' (Patient 2, coded N4.1, N4.2)

This is in direct contrast to the views of the patient who experienced side-effects and welcomed the guidelines, suggesting personal experience, rather than evidencebased science, was a key factor. Some patients also persisted in the belief that dental care is the main cause of infective endocarditis and it was difficult for them to fully accept that dental procedures have been discounted as a risk factor for infective endocarditis. For them AP was an important insurance.

'I always knew that your teeth and your heart are connected because before the surgery they always used to send me here for check ups on my teeth because it is always been quite heavily emphasised and make me a little bit nervous...' (Patient 8, line 32 Et 57, coded N7)

'Dental treatment is like an open wound, it starts bleeding and that is more of a risk of getting an infection.' (Patient 9, coded N8)

The change was seen as an unwelcome and unnecessary risk imposed on them by 'others':

'I don't know how many years it was you must have antibiotic and suddenly they decide you do not need antibiotics. Did they have the experience of being sick and having operations? I don't think so.' (Patient 5, coded N8)

The second set of barriers to patient acceptance of the NICE guidelines related to practical issues around information and the provision of care. The lack of consensus with regards to the guidelines among healthcare professionals emerged as a significant barrier which caused confusion.

'It is quite confusing. My dentist here said: "We are not going to give you antibiotics any more." My cardiologist says to me just go to your GP, get a prescription, go to the pharmacy, buy it and take it yourself, forget about whatever they said. So you can imagine how it was going to think me about the same team of people.
Don't you think the first team of professionals should be aware of this, would be the cardiologists?

'Different points of view; they [policy makers] have to know about these things and think about that but they don't...' (Patient 9, coded N1)

The information provided to improve patients' knowledge about the new guidelines did not seem to be effective in changing patients' beliefs, and a number of patients viewed the guidelines as a cost cutting exercise rather than a scientific endeavour.

'I suppose mostly it is because they don't want to spend money; cost effectiveness.' (Patient 2, coded N11)

In addition, while moving from secondary to primary dental care was reported as positive by some patients, the majority were concerned about finding a new primary care dentist with appropriate expertise.

\section{Suggestions for removing barriers}

The final part of the interview explored ways of improving patient understanding and acceptance of the new guidelines. The vast majority of suggestions (shown in Table 2) revolved around the provision of information. The source of information was deemed key and the expectation was that such information was best coming from an expert clinician who was known and trusted. Furthermore, a consensus message from both dentists and cardiologists would significantly influence patients' beliefs. The majority of participants prioritised the cardiologist and said they would comply with their advice.

'They probably pay more attention to someone who talks about their heart rather than their teeth. It is not right but I think it is how public perception works.

The optimal approach, however, would be a consensual message from both dentists and cardiologists.

'I suggest they [cardiologist and dental practitioner] talk to each other and then both together tell me, yes or no.'

Additional reliable information for those interested in understanding the change in more detail was suggested.
'Reference books or reference websites or reference points for me to go and dig more and customise it to my own, that would be depend how well the explanation is, isn't it? but obviously, stuff like this to me is like very, very valuable.'

Also suggested were statistics to support the argument made:

I suppose statistics (that are real) could help. For example there is very little evidence to say anybody is going to get IE from having dental treatment. I suppose that, if it is true.'

And ideally this should be accompanied by the provision of time and space for asking questions and discussing concerns.

'I think when the patients see the dentist and cardiologist often they are quite intimidated so they don't really ask questions they just know and agree and then they worry afterwards.'

Thus, the ideal approach would be the provision of a consensual message from a trusted expert clinician supported with written information and presented with time and space for questions.

This said, the more anxious patients wanted the option to have their case assessed individually and to be allowed to continue with AP, if they wished.

'I think you should take each case individually, if somebody is really worried [people with IE] and really anxious and if $A P$ it is not expensive and it is not really a huge financial implication.'

They also wanted the option to continue being treated in a specialist dental department, even without AP, just in case.

'...the fact that you're in a hospital as well, having treatment, there's a lot of reassurance, you know, even if I flake out here there's somebody around...'

\section{DISCUSSION}

NICE recommendations in 2008 brought to an end the assumption that antibiotic prophylaxis before dental treatment for 'at risk patients' is essential. Implementation of the guideline requires a substantial change in dental practice. This study suggests that patients have major concerns regarding the changes proposed in the guidance. Patient factors are a powerful 
influence over change. ${ }^{13,14}$ In this study participants identified potential facilitators and barriers to implementation of the NICE guideline. Participants believed in scientific progress and understood the need to change standards of care and to improve healthcare outcomes, but preferred to be considered individually for the application of such guidelines. They appeared aware of the potential harmful effects of bacterial resistance and allergic reaction following the use of antibiotics, but counterbalanced these with the belief that AP was an insurance against getting IE. This made them highly resistant to change. Unsurprisingly, this belief was stronger in the participants who had experienced an acute IE and were informed that dental treatment could be a possible reason. Participants were relieved to be individually assessed and have the option to continue with prophylaxis if they wanted. Concerns over allergy and resistance were deemed less important than the fear of IE recurrence.

Confusion, conflicting advice and awareness of different guidelines in different countries led to uncertainty about the reliability of the guideline. The role of economic motivators was also posited. Confusion among patients due to inconsistent advice being given on what is considered best practice was also found to be an important barrier in a survey conducted in Ireland. ${ }^{16}$ The results of this survey showed that nearly $80 \%$ of patients felt they would require either written or verbal confirmation from a cardiologist before considering any change to their prophylactic regimen. Anticipating difficulties in implementation of the guidance, the British Cardiac Society (BSC) advised its members 'not to feel under undue pressure to change their practice and that patients who wished to continue with antibiotic prophylaxis should be allowed to do so. Indeed, in the absence of definitive evidence, the Society views this issue as "a matter of conscience" and will support any member who chooses to recommend AP in selected circumstances. ${ }^{20}$

Clinical practice guidelines (CPGs) are one of the traditional approaches to decreasing the gap between evidence and practice and improving uptake of research findings. ${ }^{15}$ CPGs attempt to link medical practice closely to the body of underlying evidence and shift the burden of evidence review from the individual practitioner to experts to improve the quality of care. Nevertheless, with more emphasis on patient-centred practice, patients' experience and views should be considered when developing implementation plans for such guidelines. Bringing patients into the process of guideline development is an important part of making the process less clinician-lead and ensuring that the patient perspective informs the guideline development process. ${ }^{21}$ It seems apparent from this study that the patients affected by the guideline should be intrinsically involved in the guideline's development and implementation. However, in the application of any evidence the context of the discussion between an individual clinician and patient are seen as something that must be negotiated..$^{21}$ The importance of considering patients' views in the implementation of guidance is enshrined within the NICE guideline:

'Treatment and care should take into account patients' needs and preferences. Patients should have the opportunity to make informed decisions about their care and treatment, in partnership with their healthcare professionals. ${ }^{5}$

The results of this study raise valuable insights into possible patient-related barriers and facilitator factors that impact upon the implementation of the NICE guideline. Clarifying underlying barriers enables us to design a targeted intervention and/or educational program to reduce barriers and facilitate applying the NICE guideline in practice.

There were potential limitations to our study. All participants interviewed were referred by general dental practitioners or cardiologists to the hospital to receive special care for their dental treatments. They were categorised as high risk patients for IE according to the previous guidelines and had repeatedly been informed of the need for antibiotic cover over many years. It is highly likely that this situation has influenced their beliefs and has potentially made them more resistant to change. Moving from hospital care to primary care was another matter of concern in this group. Many of the participants in our study also had experience of infective endocarditis with the possibility of dental treatment as a cause. They received AP in the belief that it can prevent the recurrence IE. The implementation of the new guideline may be easier for new patients without a history of AP for dental treatment.

\section{CONCLUSIONS}

Our study investigated the possible barriers to adherence of a clinical practice guideline through face-to-face interviews with patients. To reduce patients' anxiety in applying the NICE guidelines in clinical practice, it is important that patients are given consistent messages by healthcare professionals. It is the clinician's responsibility to find out what patients want, help them find the right information, and support them in any decision making process. Patient decision support tools such as pamphlets, videos and websites would help to educate patients and improve understanding of the changes in guidance implementation.

The study was supported by the Ministry of Health and Medical Education, Tehran, Iran as part of the PhD project of the first author (SS) in King's College London. The authors would like to acknowledge the contribution of all those patients who participated in this study.

1. Ito H O. Infective endocarditis and dental procedures: evidence, pathogenesis, and prevention. J Med Invest 2006; 53: 189-198.

2. Prendergast $B D$. The changing face of infective endocarditis. Heart 2006; 92: 879-885.

3. Wilson W, Taubert K A, Gewitz M et al. Prevention of infective endocarditis: guidelines from the American Heart Association. Circulation 2007; 116: $1736-1754$

4. Gould K F, Elliott T S J, Foweraker J et al. Guidelines for the prevention of endocarditis: report of the working party of the British Society for Antimicrobial Chemotherapy. J Antimicrob Chemother 2006; 57: 1035-1042.

5. National Institute for Health and Clinical Excellence Prophylaxis against infective endocarditis: antimicrobial prophylaxis against infective endocarditis in adults and children undergoing interventional procedures. Clinical guideline 64. London: NICE, 2008.

6. Department of Health. NICE guidance on 'Antibiotic prophylaxis against infective endocarditis.' Department of Health Chief Dental Officer Letter. London: Department of Health, 2008. http:// www.dh.gov.uk/en/Publicationsandstatistics/ Lettersandcirculars/Professionalletters/ Chiefdentalofficerletters/DH_083679.

7. Harvey B. New guidance on antibiotic prophylaxis. Medical Defence Union website 2 April 2008. Available at: http://www.the-mdu.com.

8. Grimshaw J M, Shirran L, Thomas R et al. Changing provider behaviour: an overview of systematic reviews of interventions. Med Care 2001; 39(8 Suppl 2): ||2-||45.

9. Prior M, Guerin M, Grimmer-Somers K. The effectiveness of clinical guideline implementation strategies - a synthesis of systematic review findings. J Eval Clin Pract 2008; 14: 888-897.

10. NHS Centre for Reviews and Dissemination. Getting evidence into practice. Effective Health Care 1999; 5(1). http://www.york.ac.uk/inst/crd/EHC/ehc51.pdf

11. Watt R, McGlone P, Evans D et al. The facilitating factors and barriers influencing change in dental practice in a sample of English general dental practitioners. Br Dent J 2004; 197: 485-489. 
12. Cabana M D, Rand C S, Powe N R et al. Why don't physicians follow clinical practice guidelines? A framework for improvement. JAMA 1999. 282: 1458-1465.

13. Oxman A D, Thomson M A, Davis D A, Haynes B. No magic bullets: a systematic review of 102 trials of interventions to improve professional practice. Can Med Assoc J 1995; 153: 1423-1431.

14. Haines A, Donald A. Getting research findings into practice: making better use of research findings. BMJ 1998; 317: 72-75
15. Grol R, Grimshaw J M. From best evidence to best practice: effective implementation of change in patients' care. Lancet 2003; 362: 1225-1230.

16. Ni Riordáin R, McCreary C. NICE guideline on antibiotic prophylaxis against infective endocarditis: attitudes to the guideline and implications for dental practice in Ireland. Br Dent J 2009; 206: E11.

17. Newton T, Scambler S. Use of qualitative data in oral health research. Community Dent Health 2010 27: 66-67.

18. Ritchie J, Spencer L. Qualitative data analysis for applied policy research. In Bryman A, Burgess R (eds) Analysing qualitative data. pp 173-194. London: Routledge, 1994.

19. Pope C, Zeibland S, Mays N. Analysing qualitative data. BMJ 2000; 320: 114-116.

20. Boon N. British Cardiovascular Society antibiotic prophylaxis against infective endocarditis position statement. London: British Cardiovascular Society, 2008.

21. Krahn M, Naglie G. The next step in guideline development: incorporating patient preferences. JAMA 2008; 300: 436-438. 